・研究报告・

\title{
西双版纳兰科植物集市贸易特点和保护启示
}

\author{
宋亚琼1,3\# 刘芝龙 ${ }^{1 \#}$ Sophie Willian ${ }^{1}$ 高江云 $^{2 *}$ \\ 1 (中国科学院西双版纳热带植物园综合保护中心, 云南预腊 666303) \\ 2 (云南大学生态学与进化生物学实验室, 昆明 650091) \\ 3 (中国科学院大学, 北京 100049)
}

\begin{abstract}
摘要: 西双版纳是我国兰科植物多样性的热点地区之一。本文对该地区 6 个主要的集贸市场开展了为期 1 年(每月 1 次)的兰科植物贸易调查, 以了解该地区野生兰科植物采集和贸易的特点及趋势, 为兰科植物的有效保护提供依 据。本次调查共记录到兰科植物 38 属 107 种, $87.9 \%$ 的种类为附生兰, 除铁皮石斛(Dendrobium officinale)外, 其余均 为野生采集。在记录到的106种野生采集的兰科植物中, $93.4 \%$ 为西双版纳原生分布种, 约占该地区野生兰科植物 总数的 $1 / 4$, 但大多数种类的记录频次都很低, 记录频次在 10 次以上的仅有 14 种, 说明该地区兰科植物的采集和贸 易在种类上具有一定的普遍性和随意性。市场上的兰花售卖者大多数都为当地居民, 他们将采集和出售兰花作为 经济收入的来源和部分补充。本次调查没有发现跨边境兰花的采集和贸易。西双版纳兰科植物的贸易具有明显的 传统性、地域性和季节性, 4-6月为兰花贸易的高峰期。石斛属(Dendrobium)植物是最主要的贸易对象, 共记录到 35 种, 占总数的 $32.7 \%$, 记录频次最多的种类也都是石斛属植物。本地区药用石斛人工集约化栽培的快速发展并没 有减少对野生石斛的采集，反而在一定程度上刺激和促进了市场上的野生石斛贸易。通过对兰花贸易特点的分析， 我们针对该地区兰科植物的有效保护提出了针对性的建议, 包括应尽快制定和颁布地方性的法律法规, 维护和传 承本地区传统的植物文化, 对古茶园和龙山林等进行持续的保护和采用传统方式管理, 开展有针对性的公众教育 和宣传来提高公众的保护意识, 以及大力发展药用石斛的生态栽培, 使更多的当地居民参与其中, 并获得收益, 从而减少对野生资源的采集。
\end{abstract}

关键词：兰花贸易；保护；石斛产业；过度采集；西双版纳

\section{Characteristics of the orchid trade at public markets and implications for conservation in Xishuangbanna, Yunnan, China}

\author{
Yaqiong Song ${ }^{1,3 \#}$, Zhilong Liu ${ }^{1 \#}$, Sophie Willian ${ }^{1}$, Jiangyun $\mathrm{Gao}^{2 *}$ \\ 1 Center for Integrative Conservation, Xishaungbanna Tropical Botanical Garden, Chinese Academy of Sciences, Mengla, Yun- \\ nan 666303 \\ 2 Laboratory of Ecology and Evolutionary Biology, Yunnan University, Kunming 650091 \\ 3 University of Chinese Academy of Sciences, Beijing 100049
}

\begin{abstract}
The Xishuangbanna region is one of the orchid hotspots in China. To understand the characteristics and trends of the orchid trade in the region, we surveyed six public markets in 2015 . We identified and recorded 107 orchid species, belonging to 38 genera. Among them, 87.9\% of the species were epiphytic. Apart from Dendrobium officinale, all species were collected in the wild. Among the 106 wild-harvested species, 93.4\% were originally distributed to Xishuangbanna, and represented a quarter of the total species found in the area. The record frequencies of most species were very low. Only 14 species were recorded more than ten times, suggesting that the collection and trade of wild orchids was not systematic. Most of the sellers were local people. Collecting wild orchids for sale was not their main economic activity, and none of them collected or traded orchids across international borders. The highest abundance of orchids was recorded between April and June. Dendrobium species were traded the most. In total, 35 Dendrobium species were identified,
\end{abstract}

收稿日期: 2017-01-21; 接受日期: 2017-03-09

基金项目: 国家自然科学基金面上项目(31470450)和中国博士后科学基金特别资助项目(Y2BSH11B07)

\# 共同第一作者 Co-first authors

* 通讯作者 Author for correspondence. E-mail: jiangyun.gao@ynu.edu.cn 
representing $32.7 \%$ of all the recorded species. Dendrobium species had also the highest recorded frequencies. Although recently the area has seen rapid development of commercial cultivations of medicinal Dendrobium orchids, this development does not seem to have reduced the harvesting pressure on wild Dendrobium species and on the contrary, may have encouraged it. Based on market surveys, we make several conservation suggestions targeting orchids in the area.

Key words: orchid trade; conservation; Dendrobium industry; over-harvesting; Xishuangbanna

兰科是被子植物中种类最为丰富的大科之一, 全世界约有736属28,000多种(Chase et al, 2015), 但 同时它也是全球最为濒危的植物类群, 已成为植物 保护中的旗舰类群(罗毅波等, 2003; Baillie et al, 2004)。生境丧失和过度采集被认为是很多兰科植物 受威胁并濒临灭绝的两大主要原因(Hágsater \& Dumont, 1996; Pillon \& Chase, 2007; Swarts \& Dixon, 2009)。由于很多兰科植物具有较高的观赏、药用和 其他经济价值, 全球不同国家和地区都存在兰花贸 易，特别是一些兰科植物分布的热点地区，如东南 亚地区就有着悠久的兰花贸易历史, 这也是导致很 多兰科植物濒危的重要原因(Cribb et al, 2003; Phelps, 2015; Phelps \& Webb, 2015), 《濒危野生动植物种国 际贸易公约》(CITES) 把所有的野生兰科植物均列 入其保护的范围，约占该公约保护物种的 $75 \%$ 。

我国是兰科植物种类较为丰富的国家之一, 已 知有 187 属 1,447 种, 以西南地区多样性最高(张殷波 等, 2015)。云南省西双版纳是我国兰科植物多样性 的热点地区之一, 有115属428种(高江云等, 2014; Liu et al, 2015), 尤其是一些热带药用兰科植物种类 异常丰富, 如石斛属(Dendrobium)有48种, 占我国 该属植物种类的一半以上(高江云等, 2014), 包括被 《中华人民共和国药典》(国家药典委员会, 2010)收 录的金钗石斛(D. nobile)、鼓桘石斛(D. chrysotoxum)、流苏石斛(D. fimbriatum)等。我国有着历史 悠久的兰花文化，广大人民群众喜兰爱兰，同时， 约 $1 / 4$ 的兰科植物被作为传统中药材或保健食品使用 (罗毅波等, 2003; Liu et al, 2014)。很多地方都有野生 兰科植物采集和交易现象, 这也导致我国兰科植物 的保护形势尤为严峻。我国对兰科植物的需求长期 依赖野生资源的采集, 在西双版纳, 包括不同种类 的石斛、金线兰(Anoecochilus roxburghii)等药用兰 科植物在 20 世纪80-90年代都经历了大规模的采集 收购, 使得野生资源遭到了毁灭性的破坏(高江云 等, 2014)。研究表明, 在西双版纳, 不同兰科植物的
濒危等级与其利用价值(药用或观赏)显著相关，说 明过度采集是导致本地区兰科植物濒危的主要因 素(Liu et al, 2015)。

近20年来，由于野生资源的减少、保护力度的 加强以及以药用石斛为代表的药用兰科植物人工 规模栽培的快速发展，西双版纳对野生兰科植物的 采集和贸易显著减少，但在一些集贸市场，野生兰 科植物贸易仍然长期存在。本文对西双版纳几个主 要集贸市场中的兰科植物交易情况进行了为期一 年的调查, 以了解目前该地区野生兰科植物采集和 贸易的特点及趋势，同时关注是否存在跨边境的兰 花采集和贸易，探讨石斛产业的快速发展是否能有 效替代野生石斛的采集，在此基础上，对区域性兰 科植物的有效保护提供建议。

\section{1 材料和方法}

\section{1 调查地点和市场选择}

西双版纳傣族自治州位于云南省南部 $\left(21^{\circ} 09^{\prime}-\right.$ $22^{\circ} 36^{\prime} \mathrm{N}, 99^{\circ} 58^{\prime}-101^{\circ} 50^{\prime} \mathrm{E}$; alt. 480-2,430 m), 属东 南亚热带北缘地区, 由景洪市、预腊县和预海县组 成, 与老挝和缅甸接壤, 年平均气温 $22^{\circ} \mathrm{C}$, 年降水 量 1,200-1,556 mm, 有明显的雨季(5-10月)和干季 之分, 其中雨季降雨量占 $80 \%$ 。

通过前期的调查了解，我们选取了西双版纳 6 个有代表性的集贸市场, 为避免详细信息公布后加 剧兰花贸易, 本文用罗马字母代替具体的集贸市场 名称, 其中景洪市 2 个(i、ii), 预海县 1 个(iii), 预腊县 3 个(iv、v、vi)。集市 $i 、 i v 、 v$ 为较大的综合集贸市 场, 集市ii和iii是路边集贸市场, 有较多的车辆停留 购物，集市vi为边境两国边民互市集贸市场。

\section{2 调查时间和方法}

于2015年1-12月对6个集贸市场的兰花交易情 况进行每月 1 次的调查。因西双版纳很多当地居民 仍然有每周末上午赶早集的习惯，故定为每月的第 1 个星期六和星期日上午依次对 6 个集市进行调查。 
调查采取观察记录和访谈相结合的方法, 由具有一 定兰科植物分类学知识的调查人员以顾客的身份 对每一个集贸市场销售兰科植物的推位进行调查, 观察和记录所有销售的兰花种类, 估测数量和售卖 状态等, 对于不确定的种类, 先拍照, 再找分类人 员或查阅相关资料进行鉴定; 同时根据植株形态 (根、茎、叶、植株大小和整齐度等), 判定售卖植株 来源是野生采集或人工栽培; 通过交谈, 了解售卖 者的基本情况、兰花的来源、销售价格、目标用途 等情况。

\section{3 数据分析}

将调查数据按照调查地点进行每月和全年的 汇总分析, 统计每一种贸易兰科植物出现的频次及 存在该种类交易的集贸市场的数量等。依据已有资 料标注每一种记录到的兰科植物的区域性评估的 濒危等级(高江云等, 2014; Liu et al, 2015)、《中国 物种红色名录》评估的濒危等级(汪松和解炎, 2004) 及利用价值(药用、观赏或无利用价值) (朱华和间立 春, 2012; 高江云等, 2014)。采用SPSS 20.0中的单因 素方差分析的多重比较方法, 分析记录频次在不同 利用价值的兰科植物之间是否存在显著性差异(具 有 2 种利用价值的种类分别计数), 图形的绘制使用 Origin 8.0。

\section{2 结果}

\section{1 兰科植物的种类和组成特点}

在6个集贸市场共记录到兰科植物 38 属 107 种, 其中附生兰 94 种，占 $87.9 \%$; 仅有少量地生兰 $(13$ 种, 占 $12.1 \%$ )。没有发现腐生种类(附录 1 )。在所有交易 的兰科植物中，除铁皮石斛(Dendrobium officinale) 为人工大棚栽培外, 其余 106 种都为野生采集的, 且有 99 种为西双版纳原生分布种, 约占该地区野生 兰科植物总数的 $1 / 4$ 。

石斛属植物是该地区最主要的贸易对象, 6 个 市场共记录到 35 种，占总数的 $32.7 \%$ 。其他种类较多 的属依次为石豆兰属 (Bulbophyllum) 8 种、兰属 (Cymbidium) 7种、贝母兰属(Coelogyne) 6种、苹兰 属(Pinalia) 5种和石仙桃属(Pholidota) 4种, 其余32 属仅记录到1-3种(图1, 附录1)。所有种类记录到的 频次在 1-53次之间, 其中记录频次大于 40 次的有 3 种, 分别是球花石斛(D. thyrsiflorum) (53次)、鼓槌 石斛(51次)和石斛(D. nobile) (42次); 记录频次在
21-40次的有 2 种, 分别为翅蓦石斛(D. cariniferum) (32次)和长苏石斛(D. brymerianum) (28次); 11-20次 的有 9 种，其余 93 种记录频次在 10 次及以下(图 2 , 附 录1)。

依据Liu等(2015)的区域性评估结果, 在记录到 的38属106种野生兰科植物中, 有36属99种为区域 性评估收录种, 其中 20 属46种为区域性受威胁的种 类：濒危(Endangered，EN) 15种，易危(Vulnerable， VU) 31种; 没有极危(Critically Endangered, CR)物 种, 另有 52 种为无危(Least Concern, LC), 1 种数据 缺乏(Data Deficient, DD)。7种区域性评估未收录种 可能为相邻地区输入种类, 包括象牙白(Cymbidium maguanense)、喉红石斛(D. christyanum)、细叶石斛 (D. hancockii)、美冠兰(Eulophia dabia)、云南曲唇 兰(Panisea yunnanensis)、带叶兒兰(Paphiopedilum hirsutissimum)和云南石仙桃(Pholidota yunnanensis) (附录1)。《中国物种红色名录》收录的有38属103种, 包括极危 5 种, 如多花指甲兰(Aerides rosea)、麦穗石

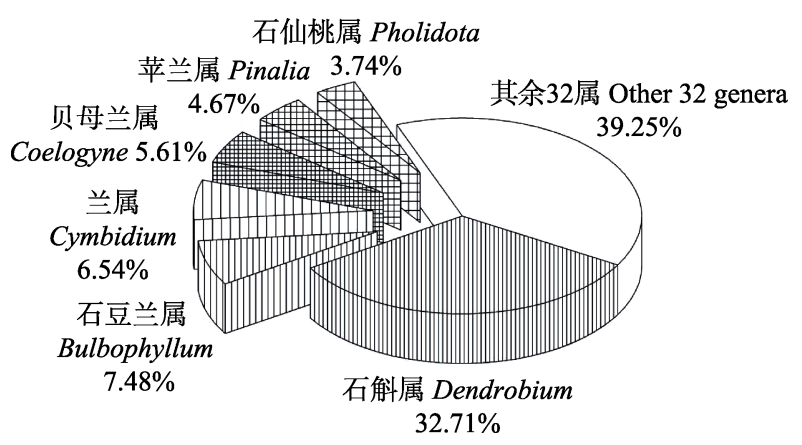

图1 西双版纳贸易兰科植物的种类构成

Fig. 1 Species composition of trade orchids in Xishuangbanna

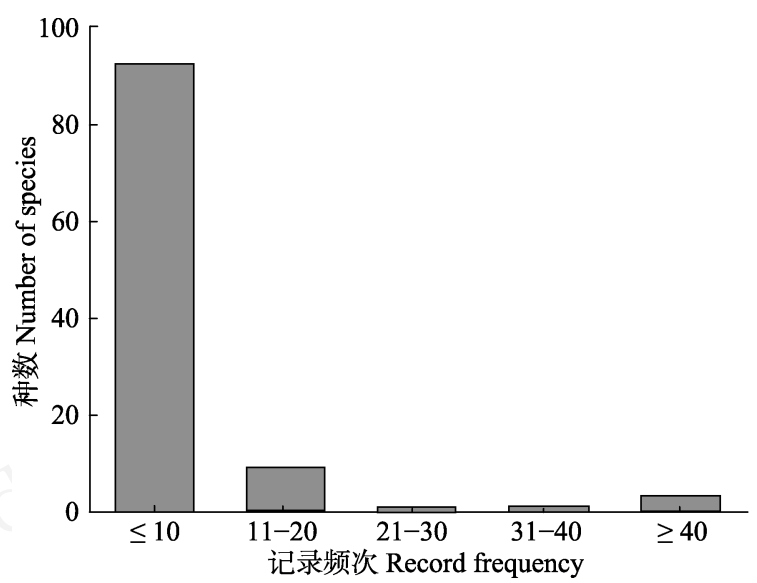

图2 西双版纳贸易兰科植物记录频次分布

Fig. 2 Record frequency of trade orchid in Xishuangbanna 
豆兰(Bulbophyllum orientale)、等䒓卷瓣兰(Bulbophyllum violaceolabellum)、苏瓣石斛(D. harvey anum) 和凤蝶兰(Papilionanthe teres); 濒危48种、易危34 种和近危(Near Threatened, NT) 16种。

\section{2 售卖者构成和销售情况}

通过与售卖者的访谈, 发现6个集市的兰花售 卖人员的组成各不相同。集市 $\mathrm{i} 、 \mathrm{v}$ 和 $v i$ 的售卖人员 主要是不固定的各地赶集农民，他们往往是到集市 购买或销售其他农产品时顺便售卖兰花。这样的售 卖者没有固定的摊位，所售卖的兰花均为自己空闲 时到山里采集或在其他采集活动中顺便采集, 放在 家里积攒一定时间后再拿到集市出售。他们对所售 卖的兰花并不了解, 有的是觉得开花好看而采集, 更多的是把不同种类的石斛和其他属兰科植物, 特 别是植株形态和石斛相似的种类, 如石仙桃属、石 豆兰属、金石斛属(Flickingeria)、美柱兰(Callostylis rigida)等当作药用石斛进行销售, 也有把禾叶贝母 兰(Coelogyne viscosa)等作为兰属植物进行销售的, 而询问价格的购买者也同样对兰花不了解。

集市ii和iii的售卖人员相对固定，都是当地居 民长期自发形成的路边集贸市场。集市ii有2户经营 农产品的居民, 他们有固定摊位, 同时销售农产品 与兰花，兰花为自己到附近山中采集，偶尔也收购 附近农民采集的种类。他们对兰花知识的了解有限, 所售卖的种类相对较少, 通常为附近山区常见且观 赏价值较高的石斛属植物, 其他观赏价值较低的类 群偶见售卖, 但售价通常较低, 并有虚构药效向顾 客推销的情况。集市iii以1户专门经营野生兰花的当 地居民为主, 常年收购和囤积各种兰花, 已形成一 定规模, 其售卖者具备一定的兰花分类知识; 另外 还有一些不固定的售卖者，其情况和前面的集市 $i$, $\mathrm{v}$ 和vi相似。

集市iv的兰科植物销售主要来自周边一户农民， 他具有一定的植物知识背景, 无固定摊位, 通常在 周末及其他人流较多的节假日携带各类有观赏或 药用价值的野生植物前来销售。其所销售的兰花全 部来自周边山区采集的野生资源, 采集后有初步的 假植或驯化行为, 售卖的兰科植物种类以具有观赏 及药用价值的石斛属植物为主。购买人群主要为当 地居民, 因观赏需求而购买的消费者比例较高。在 调查后期, 通过访谈得知, 该摊贩发现附生兰带桩 销售价值较高后, 特意将所采集的部分附生兰重新
表1 西双版纳6个集贸市场销售的兰花种属组成

Table 1 Number of orchid genera and species identified at six targeted markets in Xishuangbanna

\begin{tabular}{lll}
\hline $\begin{array}{l}\text { 集贸市场 } \\
\text { Markets }\end{array}$ & $\begin{array}{l}\text { 属数 } \\
\text { Number of genera }\end{array}$ & $\begin{array}{l}\text { 种数 } \\
\text { Number of species }\end{array}$ \\
\hline i & 14 & 35 \\
ii & 14 & 29 \\
iii & 34 & 91 \\
iv & 10 & 20 \\
v & 7 & 29 \\
vi & 1 & 5 \\
\hline
\end{tabular}

定植驯养于木桩上, 并以较小规模向周边地区的兰 科植物销售者供货。

从兰花销售的种类和数量来看, 集市iii记录到 的兰科植物种类最多，为34属91种，其余依次为集 市i、ii、V、iv和vi (表1)。球花石斛、鼓槌石斛、石 斛、翅蒠石斛和长苏石斛最为常见, 在本次调查的 6 个集市均有发现, 平均出现频次在 $30 \%$ 以上。短棒石 斛(D. capillipes)、玫瑰石斛(D. crepidatum)、流苏石 斛和报春石斛( D. polyanthum)出现于 5 个集市, 是较 为常见的种类。美冠兰、多穗兰(Polystachya concreta)、长苞苹兰(Pinalia obvia) 等 27 种出现于单一集 贸市场, 出现频次只有 $1.1-5 \%$, 为最不常见的种类 (附录1)。

\section{3 兰科植物的来源和市场交易的特点}

通过与推贩的访谈发现，不同市场交易的兰科 植物来源存在差异。集市 $\mathrm{i} 、 \mathrm{ii} 、 \mathrm{iv}$ 和 $\mathrm{v}$ 所出售的兰科 植物几乎全部来自其市场所在地周边山区野生兰 科植物的采集，通常为售卖者自采自销。集市 vi仅 调查到 2 次有兰花出售, 较为偶然。集市iii的销售者 在摊位形成一定规模后，通常不参与野外采集，而 采取收购的方式。收购所得的兰科植物的来源通常 有以下几种: (1)市场所在地周边山区野生兰科植物 的采集, 且是其最主要的来源; (2)西双版纳周边地 区的野生兰科植物采集; 包括普洱及与西双版纳接 壤的老挝、缅甸等地, 但种类及数量较少, 所占比 例极低; (3)人工栽培种, 但仅见铁皮石斛 1 种。

在记录的 62 种处于花期的兰科植物中, 观赏类 占42种, 包括石斛属 24 种, 兰属和万代兰属(Vanda) 各3种, 脆兰属(Acampe)、指甲兰属(Aerides)、鸟舌 兰属(Ascocentrum)、石豆兰属、贝母兰属、美冠兰 属(Eulophia)、槽舌兰属(Holcoglossum)、湿唇兰属 (Hygrochilus)、㝸兰属(Paphiopedilum)、凤蝶兰属 
(Papilionanthe)、钻㖨兰属(Sarcoglyphis)和掌唇兰属 (Staurochilus) 各1种。处于花期的兰科植物种数随季 节变化而不同：4-6月集贸市场上销售的处于花期 的兰科植物最多, 分别记录到23种、22种和16种(图 3), 这与贸易高峰期相一致; 花期种数的低峰期出 现在 $1 、 8 、 11$ 和 12 月, 8 月和 11 月是贸易低峰期, 记 录到的处于花期的兰科植物相应较少, 分别为 1 种 和 2 种; 1 月和 12 月销售的兰科植物数量相对较多, 但 1 月却未记录到处于花期的兰科植物, 12 月也仅 仅记录到2种, 说明兰科植物贸易受到除花期以外 其他因素的综合影响。

按兰科植物的利用价值将调查到的所有种类 分为观赏、药用和无目的用途3大类, 每类分别记录 到66种、57种和 25 种, 其中, 观赏类和药用类分别 包括了 41 种同时具有观赏和药用价值的种类。分析 结果表明, 记录频次在不同利用价值间存在显著差 异(One-Way ANOVA, $\mathrm{F}=4.165, P<0.05$ ), 具有观 赏和药用价值的种类记录频次显著高于无目的用 途的种类(LSD法, $P$ 分别为 0.009 和 0.008$)$, 而观赏与 药用种类之间无显著差异 $(P=0.912$; 图4)。

目前, 西双版纳市场上出售的兰科植物主要有 4种售卖状态: (1)裸根; (2)盆栽; (3)采集后人工定植 于木段; (4)附原始生长木段。对附生性兰科植物, 以上4种售卖形式均较常见; 对地生兰科植物, 仅 见裸根或盆栽式销售。售卖形式在各集贸市场上存 在差异。裸根是市场上最常见的销售形式, 在各集 贸市场上均普遍存在, 记录到的种类有金线兰、节 茎石仙桃(Pholidota articulata)、白柱万代兰(Vanda brunnea)等。而对一些处于花期或株形优美, 明显具 有较高观赏价值的个体, 摊贩往往不愿采取裸根销 售，而是对其进行盆栽或定植的方式以提高售价。 盆栽虽在各集贸市场上均有出现, 但以集市ii和iii 最常见, 石斛属、兰属等多采取盆栽的方式进行售 卖。附原始生长木段多见于集市iii, 而在其他 5 个集 贸市场偶见，记录到的种类有鸟舌兰(Ascocentrum ampullaceum)、钩梗石豆兰(Bulbophyllum nigrescens)、瓜子毛鞘兰(Trichotosia dasyphylla)等。

兰科植物的价格受多种因素的综合影响, 且摊 贩出价具有一定的随意性。主要表现在: (1)不同集 贸市场、不同摊位对兰科植物的定价表现出差异。 在诸如花期、定植方式、种类、长势等其他条件完 全相似的情况下, 对兰科植物相关知识了解越为深

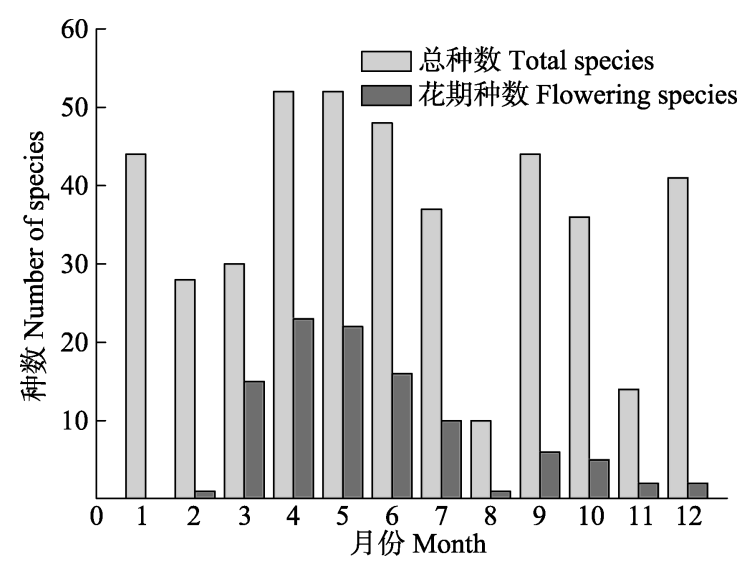

图3 西双版纳贸易兰科植物种数月变化

Fig. 3 Monthly change in trade orchids in Xishuangbanna

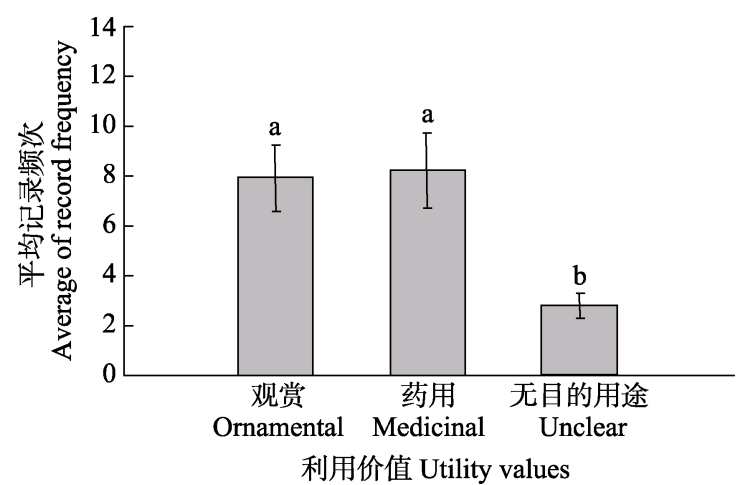

图4 西双版纳不同利用价值贸易兰科植物的记录频次(平 均值土标准误差)。不同字母表示相互间差异显著 $(\boldsymbol{P}<\mathbf{0 . 0 5})$ 。 Fig. 4 Record frequency of trade orchids with different utility values (Mean $\pm \mathrm{SE}$ ) in Xishuangbanna. Values with different letters are significantly different $(P<0.05)$.

入的推主，通常会开出更高价格，而偶尔进行贩卖 的农民摊主通常出价较低。(2)种类的差异也在价格 上有所表现。具观赏或药用的兰科植物种类, 如大 部分石斛属植物的价格明显高于其他类群。(3)处于 花期的植株价格较高, 常为非花期植株价格的 2 倍 以上。(4)不同定植方式对价格影响较大。如附原生 木段销售、多种兰花重新组合定植于木段之上或采 集后重新定植于木段或盆栽, 往往价格较高; 若为 裸根销售, 则价格相对较低。(5)植株优美、生长健 壮的个体价格较高。

\section{3 讨论}

\section{1 西双版纳野生兰花贸易的现状和特点}

西双版纳是我国陆地生物多样性保护的关键 地区(Tang et al, 2006), 也是附生兰科植物物种丰富 度最高的地区(Zhang et al, 2015), 同时还是很多兰 
科植物种类在我国的主要或唯一分布区(高江云等, 2014)。但自 20 世纪60年代以来, 随着人口增加和橡 胶种植业的迅速发展, 大量的原始森林遭到砍伐, 造成了兰科植物栖息地的丧失, 使西双版纳野生兰 科植物资源在分布范围上受到严重限制(余东莉和 刘强, 2008)。而对于一些具有较高观赏或药用价值 的兰科植物, 过度采集是造成其种群数量迅速减少 的主要原因(高江云等, 2014)。从本次市场调查的结 果来看, 西双版纳市场交易的兰科植物几乎全部来 源于野生植株的采集, 仅有铁皮石斛 1 种为人工栽 培。记录到的106种野生采集的兰科植物, 93.4\%都 为西双版纳原生分布种, 约占本地区野生兰科植物 总数的 $1 / 4$, 但大多数种类的记录频次都很低, 仅有 14 种记录频次在 10 次以上(图 2 , 附录 1 ), 说明本地 区对兰科植物的采集和贸易在种类上具有一定的 普遍性和随意性。

野生动植物贸易受到社会经济状况的影响, 既 具备一般贸易活动的特征, 又有特殊性, 一般具有 传统性、地域性、流动的方向性、季节性、分散性、 替代效应、反馈效应和补充性等特点(周志华和蒋志 刚，2005)。西双版纳是我国多民族聚居地区，各民 族在对植物的认识和利用方面积累了丰富的经验, 形成了极具地方色彩的植物文化(许再富和刘宏茂, 1995)。当地居民有利用各种兰花装点庭院和作为头 饰花卉的传统和习惯(高江云等, 2014)。本次调查中, 大多数售卖者都为当地居民, 他们通常对周边森林 很熟悉, 兰花和其他林产品如野菜、野果、蘑菇、 药材等一样, 是他们平时经济收入来源的一部分和 补充, 他们对兰花的采集在种类上并没有专门的选 择, 株形或开花漂亮的种类及一些认为可以药用的 种类通常是采集和贸易的对象。这也是我们记录到 兰花种类极为丰富的主要原因。西双版纳属热带地 区, 以附生种类为主的兰科植物极为丰富, 这也体 现在市场贸易上。和国内其他兰花市场不同, 受传 统的“国兰”文化影响较小, 该地区仅有零星的建兰 (Cymbidium ensifolium)和墨兰(Cymbidium sinense) 出售, $87.9 \%$ 的种类都为附生兰。从利用价值来看, 记录到的兰科植物也大致可分为观赏和药用 2 类, 由于形态分类的困难, 很多并没有药用价值的种类 也被作为药用兰花进行交易。石斛属很多植物既具 有较高的观赏价值, 同时也有药用价值, 成为市场 贸易的主要种类, 无论是种类和记录频次都是最多
的类群(图1)。其他观赏价值较高的种类如多花指甲 兰、大花万代兰(Vanda coerulea)等也较常见。

野生动植物贸易因生物生长周期的不同而呈 现一定的季节变化(周志华和蒋志刚, 2005; 李友邦 等, 2010)。西双版纳贸易兰科植物种数也表现出明 显的季节更替，各月份贸易种类组成不同。4-6月为 西双版纳气温最高的干热季, 开花的兰科植物种类 最多(高江云等, 2014), 也是兰花贸易高峰期, 共统 计到贸易兰科植物 31 属 77 种, 其中处于开花期的有 60 种，占总数的 $77.9 \% ; 8$ 月为各种野生蘑菇上市的 季节，采集者都忙于采集市场价值更高的野生蘑菇， 兰花交易骤减, 仅记录到 10 种兰科植物(图3, 附录 1)。种群大小和易获得性是影响野生动植物贸易活 动的重要生物因素(周志华和蒋志刚, 2005)。本次调 查记录到的兰科植物中, 没有区域性评估为极危的 物种, 也说明这些种类在野外数量极少, 难以获得, 而记录频次较高的种类都是在本地区海拔分布范 围较广、容易获得的种类。《中国物种红色名录》 评估为极危的 5 种兰科植物均为西双版纳有唯一分 布点, 但种群数量较大。

野生动植物贸易利润丰厚, 是许多人经济收入 的重要来源。市场需求刺激了农民的捕猎和采集活 动(Lau \& Shi, 2000; Broad et al, 2003), 过度采集无 疑会对野生动植物资源的可持续利用造成严重的 威胁(Hinsley et al, 2016)。本次调查的6个集贸市场 中, 在兰科植物种类、数量和记录频次上, 集市iii 都远远高于其他 5 个市场(表 1 , 附录 1 ), 其主要经营 者以收购、击积和销售兰花为主，已经形成了较大 规模, 这已经完全不同于本地区把兰花作为普通林 产品售卖的传统方式, 对当地的兰科植物资源产生 了较大的破坏。

\section{2 商业化药用石斛栽培对野生石斛采集的影响}

西双版纳是我国石斛属植物资源最为丰富的地 区，不仅种类多、分布广，很多种类原生数量也很大， 但由于 20 世纪80-90年代中期, 大规模的扫荡式采集 使野生石解资源遭到毁灭性的破坏，很多种类已经很 难再找到自然种群, 在野外只能偶尔看到零星的个体 (高江云等, 2014)。对于过度采集的物种的保护, Wilkie 和Godoy (2001)提出了供给策略(supply-side approach) 和需求策略(demand-side approach), 并认为这是目前 最重要和最有效的保护方法。供给策略是通过栽 培、圈养等方式增加人工繁育的动植物资源的供给 
量，从而减少对野生资源的采集，同时可以增加当 地居民的收入(Williams et al, 2012)。然而，从世界 范围内的保护实践来看, 商业化的栽培(驯养)对减 少野生植物(动物)采集压力的收效甚微, 其主要原 因是栽培的产品并不能完全替代野生资源(Bulte \&

Damania, 2005; Phelps et al, 2014)。

我国药用石斛产业的发展始于 20 世纪 90 年代 末期, 以铁皮石斛为主, 主要通过种子无菌萌发和 组织培养生产种苗, 大棚集约化栽培的产业模式在 过去的10多年发展迅速。在西双版纳, 药用石斛的 栽培规模也不断扩大, 然而, 这一产业模式似乎并 没有减少对野生药用石斛的采集压力。本次调查中 发现, 32.7\%的种类为石斛属植物, 记录频次最多的 也是各种石斛, 很多其他属的兰科植物也被当作药 用石斛在出售。在我们调查的过程中, 一个有趣的 现象是市场上经常有把栽培的铁皮石斛或其他种 类的野生石斛如齿瓣石斛 $(D$. devonianum)、晶帽石 斛(D. crystallinum)、舀唇石斛(D. cucullatum)等当作 “野生”铁皮石斛出售, “野生”成了最大的卖点, 但 实际上西双版纳没有野生铁皮石斛的分布。这一现 象在其他一些濒危动植物产品的贸易中也普遍存 在(Gratwicke et al, 2008; Brooks et al, 2010)。供给策 略不但没有降低消费者对野生动植物产品的需求, 反而增加了人们对野生产品的兴趣和更大规模的 开采。野生动植物产品并不能完全被养殖和栽培的 产品所代替, 尤其对于药用动植物产品而言(Dutton et al, 2011)。

药用石斛目前的集约化栽培模式需要巨大的 基础设施、种苗和管理成本投入, 使得当地居民很 难从中获得利益(高江云等, 2014)。同时, 这种集约 化栽培模式的产品可能存在药效成分减少、农残超 标等问题, 也给消费者带来困扰。更为重要的是, 普通消费者对中药材和保健品的消费心理普遍认为 野生的药效更好、更安全, 这也使得消费者对野生 药用石斛更加偏好, 从而加剧了对野生石斛资源的 采集。本次调查并没有发现公开市场有跨边境的药 用石斛采集和贸易, 但本地区普遍存在的大量小规 模石斛种植园, 其种源完全依靠野生石斛资源, 跨 边境民间贸易仍是其最主要的来源(高江云等, 2014)。

\section{3 保护启示和建议}

兰科植物是生物多样性保护中的旗舰类群, 全 世界所有的野生兰科植物均列入了 CITES的保护范
围, 禁止国际贸易。兰科植物约占该公约保护物种 的 $75 \%$, 但在国内其保护地位却并不明确，1999年 颁布的《中国国家重点保护野生植物名录(第一批)》 并没有把兰科植物列入其中, 对兰科植物的采集和 贸易管理面临着无法可依的困境, 在适用的法律法 规上只有《中华人民共和国自然保护区条例》有所 约束。也就是说，在保护区范围以外采集兰科植物 并没有法律法规的限制。西双版纳目前各类保护区 的面积约占其面积的 $15.5 \%$, 这虽然高于全国的平 均水平, 但仍有近 $1 / 3$ 的种类不在保护区范围内, 得 不到有效、安全的保护(Liu et al, 2015)。因此, 应尽 快制定和颁布地方性的法律法规, 使兰科植物及其 他濒危植物的保护有法可依。

西双版纳以傣族为主的各少数民族在漫长的 劳动生活中形成了独特的传统文化, 对植物的认识 和利用极具地方色彩, 这些传统知识和文化的传承 和沿用对本地区森林的保护和植物资源的可持续 利用发挥了重要作用(许再富和刘宏茂, 1995)。由于 土地利用方式发生了巨大变化, 该区森林严重破碎 化和片断化, 传统的古茶园和龙山林成为很多兰科 植物的栖息地和避难所(Liu et al, 2015; Zhou et al, 2016)。维护和传承传统的植物文化, 以及对古茶园 和龙山林等进行持续的保护和采用传统方式管理, 对于兰科植物的保护也将起到重要作用。

对于像兰花这样遭过度采集的植物来说, 通过 开展有针对性的公众教育活动和广泛的媒体宣传 来提高公众的保护意识同样非常重要, 也就是前文 提到的需求策略(Wilkie \& Godoy, 2001)。社会公众 作为生物多样性保护最直接的利益相关者, 是生物 多样性保护的重要力量, Global Strategy for Plant Conservation (https://www.cbd.int/decision/cop/default. $\operatorname{shtml}$ ?id=7183) 也提出要将公众宣传和教育摆在促 进植物多样性保护的优先发展位置。研究实例表明, 在对公众进行环境教育后，消费者对濒危海产品的 购买意向呈下降趋势(Eriksson \& Clarke, 2015)。可 通过开展各种形式的宣传教育活动, 让公众认识到 野生兰花目前所面临的严重威胁, 唤起公众对野生 兰花的保护意识。

本次调查中, 药用石斛是市场贸易最主要的对 象。针对目前我国药用石斛集约化栽培模式所带来 的问题, 一些学者也提出了兼顾野生种群保护和经 济效益的“恢复友好型栽培模式(restoration-friendly 
cultivation model)” (Liu et al, 2014), 也就是在自然 条件下开展药用石斛的生态栽培, 使更多的当地居 民参与其中, 获得收益, 从而减少对野生资源的采 集。这一模式具有基础设施投入小, 全过程绿色无 农药无化肥污染等优点, 能从根本上满足消费者对 野生石斛的需求。药用石斛的生态栽培目前也成为 石斛业界的共识和产业发展的重要方向, 一些相关 的研究成果也不断出现, 如利用有效共生真菌开展 石斛种子的共生萌发(Zi et al, 2014; 字肖萌和高江 云, 2014), 分离共生真菌用于促进石斛幼苗的生长 (黄晖等, 2016)等, 这些技术、成果的不断完善和在 实际生产中的应用, 必将极大地促进和带动药用石 斛生态栽培的发展, 对野生石斛资源的保护产生重 要作用。

\section{参考文献}

Baillie JEM, Hilton-Taylor C, Stuart SN (2004) 2004 IUCN Red List of Threatened Species: A Global Species Assessment. IUCN, Gland, Switzerland.

Broad S, Mulliken T, Roe D (2003) The nature and extend of legal and illegal trade in wildlife. In: The Trade in Wildlife: Regulation for Conservation (ed. Oldfield S), pp. 3-22. Earthscan Publications, London.

Brooks EGE, Roberton SI, Bell DJ (2010) The conservation impact of commercial wildlife farming of porcupines in Vietnam. Biological Conservation, 143, 2808-2814.

Bulte EH, Damania R (2005) An economic assessment of wildlife farming and conservation. Conservation Biology, 19, 1222-1233.

Chase MW, Cameron KM, Freudenstein JV, Pridgeon AM, Salazar G, Berg C, Schuiteman A (2015) An updated classification of Orchidaceae. Botanical Journal of the Linnean Society, 177, 151-174.

Cribb PJ, Kell SP, Dixon KW, Barrett RL (2003) Orchid conservation: a global perspective. In: Orchid Conservation (eds Dixon KW, Kell SP, Barrett RL, Cribb PJ), pp. 1-24. Natural History Publications, Kota Kinabalu, Sabah.

Dutton AJ, Hepburn C, Macdonald DW (2011) A stated preference investigation into the Chinese demand for farmed vs. wild bear. PLoS ONE, 6, e21243.

Eriksson H, Clarke S (2015) Chinese market responses to over exploitation of sharks and sea cucumbers. Biology Conservation, 184, 163-173.

Gao JY, Liu Q, Yu DL (2014) Orchids of Xishuangbanna: Diversity and Conservation. China Forestry Publishing House, Beijing. (in Chinese) [高江云, 刘强, 余东莉 (2014) 西双 版纳的兰科植物多样性和保护. 中国林业出版社, 北京.]

Gratwicke B, Mills J, Dutton A, Gabriel G, Long B, Seidensticker J, Wright B, You W, Zhang L (2008) Attitudes to- ward consumption and conservation of tigers in China. PLoS ONE, 3, e2544.

Hágsater E, Dumont V (1996) Conservation threats. In: Orchids: Status, Survey, and Conservation Action Plan (ed. Prindgeon AM), pp. 6-9. IUCN, Gland, Switzerland.

Hinsley A, Lee TE, Harrison JR, Roberts DL (2016) Estimating the extend and structure of trade in horticultural orchids via social media. Conservation Biology, 30, 1038-1047.

Huang H, Shao SC, Gao JY (2016) Effects of different endophytic fungi on seedling growth of Dendrobium devonianum. China Journal of Chinese Materia Medica, 41, 2019-2024. (in Chinese with English abstract) [黄晖, 邵士 成, 高江云 (2016) 不同内生真菌对齿瓣石斛幼苗生长 的效应. 中国中药杂志, 41, 2019-2024. ]

Lau MWN, Shi HT (2000) Conservation and trade of terrestrial and freshwater turtles and tortoises in the People's Republic of China. In: Asian Turtle Trade: Proceedings of a Workshop on Conservation and Trade of Freshwater Turtles and Tortoises in Asia (eds van Dijk PP, Stuart BL, Rhodin AGJ), pp. 30-38. Chelonian Research Monographs. Lunenburg, Massachusetts.

Li YB, Wei ZY, Zou Y, Fan DY, Xie JF (2010) Survey of illegal smuggles of wildlife in Guangxi. Chinese Journal of Wildlife, 31, 280-284. (in Chinese with English abstract) [李友邦, 韦振逸, 邹异, 范丁一, 谢菊芳 (2010) 广西野 生动物非法利用和走私的种类初步调查. 野生动物, 31 , 280-284.]

Liu H, Luo YB, Heinen J, Bhat M, Liu ZJ (2014) Eat your orchid and have it too: a potentially new conservation formula for Chinese epiphytic medicinal orchids. Biodiversity and Conservation, 23, 1215-1228.

Liu Q, Chen J, Corlett RT, Fan XL, Yu DL, Yang HP, Gao JY (2015) Orchid conservation in the biodiversity hotspot of southwestern China. Conservation Biology, 29, 1563-1572.

Luo YB, Jia JS, Wang CL (2003) A general review of the conservation status of Chinese orchids. Biodiversity Science, 11, 70-77. (in Chinese with English abstract) [罗毅波, 贾 建生, 王春玲 (2003) 中国兰科植物保育的现状和展望. 生物多样性, 11, 70-77.]

Pharmacopoeia Committee of the People's Republic of China (2010) Pharmacopoeia of the People's Republic of China. China Medical Science and Technology Press, Beijing. (in Chinese) [国家药典委员会 (2010) 中华人民共和国药典. 中国医药科技出版社, 北京.]

Phelps J, Carrasco LR, Webb EL (2014) A framework for assessing supply-side wildlife conservation. Conservation Biology, 28, 244-257.

Phelps J (2015) A Blooming Trade: Illegal Trade of Ornamental Orchids in mainland Southeast Asia (Thailand, Lao PDR, Myanmar). TRAFFIC. Petaling Jaya, Selangor, Malay.

Phelps J, Webb EL (2015) "Invisible" wildlife trades: Southeast Asia's undocumented illegal trade in wild ornamental plants. Biological Conservation, 186, 296-305. 
Pillon Y, Chase MW (2007) Taxonomic exaggeration and its effects on orchid conservation. Conservation Biology, 21, 263-265.

Swarts ND, Dixon KW (2009) Terrestrial orchid conservation in the age of extinction. Annals of Botany, 104, 543-556.

Tang Z, Wang Z, Zheng C, Fang J (2006) Biodiversity in China's mountains. Frontiers in Ecology and the Enironment, 4, 347-352.

Wang S, Xie Y (2004) China Species Red List, Vol. 1: Red List. Higher Education Press, Beijing. (in Chinese) [汪松, 解炎 (2004) 中国物种红色名录(第1卷): 红色名录. 高等 教育出版社, 北京.]

Wilkie DS, Godoy RA (2001) Income and price elasticities of bushmeat demand in lowland Amerindian societies. Conservation Biology, 15, 761-769.

Williams SJ, Jones JPG, Clubbe C, Sharrock S, Gibbons JM (2012) Why are some biodiversity policies implemented and others ignored? Lessons from the uptake of the Global Strategy for Plant Conservation by botanic gardens. Biodiversity Conservation, 21, 175-187.

Xu ZF, Liu HM (1995) Plam leaves Buddhism Sutra culture of Xishuangbanna Dai and plant diversity conservation. Chinese Biodiversity, 3, 174-179. (in Chinese with English abstract) [许再富, 刘宏茂 (1995) 西双版纳傣族贝叶文化 与植物多样性保护. 生物多样性, 3, 174-179.]

Yu DL, Liu Q (2008) Biodiversity assessment and conservation strategies for wild orchid plants in Xishuangbanna National Nature Reserve. Forest Inventory and Planning, 33(6), 27-29. (in Chinese with English abstract) [余东莉, 刘强 (2008) 西双版纳国家级自然保护区野生兰科植物多样性 评价及保护对策. 林业调查规划, 33(6), 27-29.]

Zhang YB, Du HD, Jin XH, Ma KP (2015) Species diversity and geographic distribution of Orchidaceae in China. Chinese Science Bulletin, 60, 179-188. (in Chinese with English abstract) [张殷波，杜吴东，金效华，马克平 (2015) 中国野生兰科植物物种多样性与地理分布. 科学通报, 60, 179-188.]

Zhang ZJ, Yan YJ, Tian Y, Li JS, He JS, Tang ZY (2015) Distribution and conservation of orchid species richness in China. Biological Conservation, 181, 64-72.

Zhou X, Liu Q, Han JY, Gao JY (2016) Different pollination assemblages ensure reproductive success of Cleisostoma linearilobatum (Orchidaceae) in fragmented holy hill forest and traditional tea garden. Scientific Reports, 6, 21435.

Zhou ZH, Jiang ZG (2005) Features and impacting factors on trade of wildlife. Biodiversity Science, 13, 462-471. (in Chinese with English abstract) [周志华, 蒋志刚 (2005) 野 生动植物贸易活动的特点及影响因子研究. 生物多样性, 13, 462-471.]

Zhu H, Yan LC (2012) Native Seed Plants in Xishuangbanna of Yunnan. Science Press, Beijing. (in Chinese) [朱华, 间丽春 (2012) 云南西双版纳野生种子植物, 科学出版社, 北京.]

Zi XM, Gao JY (2014) Effect of different fungi on symbiotic seed germination of two Dendrobium species. China Journal of Chinese Materia Medica, 39, 3238-3244. (in Chinese with English abstract) [字肖萌, 高江云 (2014) 不同真菌 对 2 种药用石斛种子共生萌发的效应. 中国中药杂志, 39, 3238-3244.]

Zi XM, Sheng CL, Goodale MU, Shao SC, Gao JY (2014) In situ seed baiting to isolate germination-enhancing fungi for an epiphytic orchid, Dendrobium aphyllum (Orchidaceae). Mycorrhiza, 24, 487-499.

(责任编委: 龙春林 责任编辑: 黄祥忠)

\section{附录 Supplementary Material}

附录1 西双版纳兰科植物集贸市场调查结果

Appendix 1 Results of investigation on orchid trade at public markets in Xishuangbanna http://www.biodiversity-science.net/fileup/PDF/2017022-1.pdf 
宋亚琼，刘芝龙，Sophie Willian，高江云. 西双版纳兰科植物集市贸易特点和保护启示. 生物多样性, 2017, 25 (5): 531-539.

http://www.biodiversity-science.net/CN/10.17520/biods.2017022

附录 1 西双版纳兰科植物集贸市场调查结果

Appendix 1 Results of investigation on orchid trade at public markets in Xishuangbanna

\begin{tabular}{|c|c|c|c|c|c|c|c|c|c|c|c|c|c|c|c|c|}
\hline $\begin{array}{l}\text { 物种 } \\
\text { Species }\end{array}$ & $\begin{array}{c}\text { 生活型 } \\
\text { Life } \\
\text { form }\end{array}$ & $\begin{array}{c}\text { 濒危等级 } \\
\text { Endanger- } \\
\text { ment category }\end{array}$ & $\begin{array}{l}\text { 用途 } \\
\text { Usage }\end{array}$ & $\begin{array}{c}\text { 记录频次 } \\
\text { Record } \\
\text { frequency }\end{array}$ & $\begin{array}{l}1 \text { 月 } \\
\text { Jan. }\end{array}$ & $\begin{array}{l}2 \text { 月 } \\
\text { Feb. }\end{array}$ & $\begin{array}{l}3 \text { 月 } \\
\text { Mar. }\end{array}$ & $\begin{array}{l}4 \text { 月 } \\
\text { Apr. }\end{array}$ & $\begin{array}{l}5 \text { 月 } \\
\text { May }\end{array}$ & $\begin{array}{l}\text { 6月 } \\
\text { Jun. }\end{array}$ & $\begin{array}{c}7 \text { 月 } \\
\text { Jul. }\end{array}$ & $\begin{array}{l}8 \text { 月 } \\
\text { Aug. }\end{array}$ & $\begin{array}{l}9 \text { 月 } \\
\text { Sept. }\end{array}$ & $\begin{array}{c}10 \text { 月 } \\
\text { Oct. }\end{array}$ & $\begin{array}{l}11 \text { 月 } \\
\text { Nov. }\end{array}$ & $\begin{array}{l}12 \text { 月 } \\
\text { Dec. }\end{array}$ \\
\hline 多花脆兰 Acampe rigida & $\mathrm{E}$ & LC & $\mathrm{O}$ & 4 & & i & & & iii & & & & $i^{*}$ & & & iv \\
\hline 多花指甲兰 Aerides rosea & E & $\mathrm{VU}$ & $\mathrm{O}$ & 8 & iii & & & iii & ii, iii & $i, i^{*}$ & $i, i i^{*}$ & & & & & \\
\hline 滇南金线兰 Anoectochilus burmannicus & $\mathrm{T}$ & $\mathrm{EN}$ & M & 6 & i & i & & $\mathrm{v}$ & & & & & $i^{*}$ & & & \\
\hline 丽蕾金线兰 A. lylei & $\mathrm{T}$ & EN & M & 2 & $\mathrm{v}$ & & $\mathrm{v}^{*}$ & & & & & & & & & \\
\hline 金线兰 A. roxburghii & $\mathrm{T}$ & $\mathrm{EN}$ & M & 2 & & & & & & & & i & $\mathrm{v}$ & & & \\
\hline 竹叶兰 Arundina graminifolia & $\mathrm{T}$ & $\mathrm{LC}$ & $\mathrm{O} \& \mathrm{M}$ & 2 & iii & & iii & & & & & & & & & \\
\hline 鸟舌兰 Ascocentrum ampullaceum & E & $\mathrm{vU}$ & $\mathrm{O}$ & 4 & & iii & & $\mathrm{iii}^{*}$ & $i i^{*}$ & & & & & & & iv \\
\hline 赤唇石豆兰 Bulbophyllum affine & E & LC & $\mathrm{N}$ & 7 & & & & ii, iii & $\mathrm{ii}, \mathrm{iii}^{*}$ & $\mathrm{ii}^{*}$ & $\mathrm{ii}^{*}$ & & & i i & & \\
\hline 芳香石豆兰 B. ambrosia & E & LC & $\mathrm{N}$ & 4 & & & $\mathrm{iii}^{*}$ & & $i i^{*}$ & ii & ii & & & & & \\
\hline 直唇卷瓣兰 B. delitescens & $\mathrm{E}$ & $\mathrm{LC}$ & $\mathrm{O}$ & 1 & & & & & & & $\mathrm{v}^{*}$ & & & & & \\
\hline 钩梗石豆兰 B. nigrescens & $\mathrm{E}$ & LC & $\mathrm{N}$ & 12 & $\mathrm{iii}$ & iii & iii & $\mathrm{iii}^{*}$ & $\mathrm{iii}^{*}$ & & & & iii & iii & iii & iii \\
\hline 密花石豆兰 B. odoratissimum & $\mathrm{E}$ & $\mathrm{LC}$ & M & 2 & iii & & & & & & $\mathrm{ii}^{*}$ & & & & & \\
\hline 麦穗石豆兰 B. orientale & $\mathrm{E}$ & LC & M & 10 & iii & & & iii & ii & $\mathrm{ii}, \mathrm{iii}^{*}$ & $\mathrm{iii}^{*}$ & & $\mathrm{iii}^{*}$ & iii & & iii \\
\hline 聚株石豆兰 B. sutepense & $\mathrm{E}$ & LC & $\mathrm{N}$ & 1 & & & & iii & & & & & & & & \\
\hline 等蓸卷瓣兰 B. violaceolabellum & $\mathrm{E}$ & $\mathrm{EN}$ & $\mathrm{O}$ & 3 & & & & & & iii & & & iii & & & iii \\
\hline 葫芦茎虾脊兰 Calanthe labrosa & $\mathrm{T}$ & $\mathrm{vU}$ & $\mathrm{O}$ & 1 & & & & & & & & & & iii & & \\
\hline 三褶虾脊兰 C. triplicata & $\mathrm{T}$ & $\mathrm{LC}$ & M & 1 & & & & & & & & & & iii & & \\
\hline 竹叶美柱兰 Callostylis bambusifolia & $\mathrm{E}$ & $\mathrm{vU}$ & $\mathrm{N}$ & 1 & $\mathrm{iii}$ & & & & & & & & & & & \\
\hline 美柱兰 C. rigida & $\mathrm{E}$ & $\mathrm{LC}$ & $\mathrm{N}$ & 4 & ii & & & & & $\mathrm{iii}^{*}$ & & & iii & & & iv \\
\hline 毛柱隔距兰 Cleisostoma simondii & $\mathrm{E}$ & $\mathrm{VU}$ & $\mathrm{N}$ & 1 & & & & iii & & & & & & & & \\
\hline 云南贝母兰 Coelogyne assamica & $\mathrm{E}$ & $\mathrm{VU}$ & $\mathrm{O}$ & 1 & iii & & & & & & & & & & & \\
\hline 流苏贝母兰 C. fimbriata & $\mathrm{E}$ & DD & $\mathrm{O}$ & 1 & & & & & & & & & & $\mathrm{iii}^{*}$ & & \\
\hline 栗鳞贝母兰 C. flaccida & E & $\mathrm{LC}$ & M & 2 & & & & iii & & & & & & iii & & \\
\hline
\end{tabular}


宋亚琼，刘芝龙，Sophie Willian，高江云. 西双版纳兰科植物集市贸易特点和保护启示. 生物多样性, 2017, 25 (5): 531-539. http://www.biodiversity-science.net/CN/10.17520/biods.2017022

\begin{tabular}{|c|c|c|c|c|c|c|c|c|c|c|c|c|c|c|c|c|}
\hline 长鳞贝母兰 C. ovalis & E & $\mathrm{LC}$ & $\mathrm{O} \& \mathrm{M}$ & 1 & & & & & & & & & & & & iii \\
\hline 黄绿贝母兰 C. prolifera & E & $\mathrm{VU}$ & $\mathrm{N}$ & 4 & & & & & & $\mathrm{iii}^{*}$ & $\mathrm{iii}$ & & iii & & iii & \\
\hline 禾叶贝母兰 C. viscosa & E & $\mathrm{LC}$ & $\mathrm{O}$ & 1 & & & & & & & & & & iii & & \\
\hline 深裂沼兰 Crepidium purpureum & $\mathrm{T}$ & $\mathrm{LC}$ & $\mathrm{N}$ & 1 & & & & & & & & & & & & iv \\
\hline 纹瓣兰 Cymbidium aloifolium & E & $\mathrm{LC}$ & $\mathrm{O}$ & 6 & & ii & & & & $\mathrm{iii}$ & $\mathrm{iii}$ & & $\mathrm{iii}$ & $\mathrm{iii}$ & & iii \\
\hline 冬风兰 C. dayanum & E & $\mathrm{VU}$ & $\mathrm{O}$ & 3 & $\begin{array}{l}\mathrm{i}, \\
\mathrm{v}, \mathrm{iii}\end{array}$ & & & & & & & & & & & \\
\hline 建兰 C. ensifolium & $\mathrm{T}$ & $\mathrm{VU}$ & $\mathrm{O}$ & 3 & iii & & & & iii & & & & & & & iii \\
\hline 象牙白 C. maguanense & E & - & $\mathrm{O}$ & 1 & & & iii & & & & & & & & & \\
\hline 硬叶兰 C. mannii & E & LC & $\mathrm{O}$ & 10 & iii & iii & $\mathrm{iii}^{*}$ & $\mathrm{iii}^{*}$ & & $\mathrm{iii}$ & iii & iii & iii & iii & & iii \\
\hline 墨兰 C. sinense & $\mathrm{T}$ & $\mathrm{VU}$ & $\mathrm{O}$ & 3 & iii & i & & & & & & & & & $i i^{*}$ & \\
\hline 西藏虎头兰 C. tracyanum & E & $\mathrm{VU}$ & $\mathrm{O}$ & 12 & iii & $\mathrm{v}, \mathrm{iii}$ & iii & $\mathrm{iii}$ & $\mathrm{v}, \mathrm{iii}$ & iii & iii & & $\mathrm{iii}^{*}$ & $\mathrm{iii}^{*}$ & & $\mathrm{iii}^{*}$ \\
\hline 钩状石斛 Dendrobium aduncum & $\mathrm{E}$ & VU & $\mathrm{O} \& \mathrm{M}$ & 6 & i, iii & $\mathrm{v}$ & & $\mathrm{iii}$ & & & & & $\mathrm{iii}$ & & & iii \\
\hline 矮石斛 D. bellatulum & E & $\mathrm{LC}$ & $\mathrm{O} \& \mathrm{M}$ & 4 & & & & & $i^{*}$ & $i, \mathrm{iii}^{*}$ & & & & & & iii \\
\hline 长苏石斛 D. brymerianum & E & LC & $\mathrm{O} \& \mathrm{M}$ & 28 & $\begin{array}{l}\mathrm{i}, \mathrm{v}, \\
\mathrm{vi}, \mathrm{iii}\end{array}$ & i, iii & iv, iii & $\begin{array}{l}\mathrm{ii}, \mathrm{v} \\
\mathrm{iii}\end{array}$ & ii, iii & $\begin{array}{l}\mathrm{ii}, \mathrm{v} \\
\mathrm{iii}^{*}\end{array}$ & $\begin{array}{l}\mathrm{ii}, \mathrm{v}, \\
\mathrm{iii}^{*}\end{array}$ & & $\mathrm{v}, \mathrm{iii}$ & & iii & iii \\
\hline 短棒石斛 D. capillipes & E & LC & $\mathrm{O} \& \mathrm{M}$ & 10 & & iv & $\begin{array}{l}i, i i \\
i v^{*}\end{array}$ & $\begin{array}{l}i i, v \\
i v^{*}\end{array}$ & $i v^{*}$ & & & & iii & iv & & \\
\hline 翅蕒石斛 D. cariniferum & E & LC & $\mathrm{O} \& \mathrm{M}$ & 32 & $\begin{array}{l}\text { ii, vi, } \\
\text { iii }\end{array}$ & $\begin{array}{l}\text { v, vi, } \\
\text { iii }\end{array}$ & $\begin{array}{l}\text { iv, } \\
i i^{*}\end{array}$ & $\begin{array}{l}\mathrm{i}, \mathrm{ii} \\
\mathrm{v}, \mathrm{iii}^{*}\end{array}$ & $\mathrm{v}, \mathrm{iii}$ & $\mathrm{i}, \mathrm{iii}$ & $\begin{array}{l}\text { i, iv, } \\
\text { iii }\end{array}$ & $\mathrm{i}$ & $\mathrm{v}, \mathrm{iii}$ & $\mathrm{v}, \mathrm{iii}$ & iii & $\mathrm{v}, \mathrm{iii}$ \\
\hline 喉红石斛 D. christyanum & $\mathrm{E}$ & - & $\mathrm{O} \& \mathrm{M}$ & 2 & & & & & iii & $\mathrm{iii}$ & & & & & & \\
\hline 束花石斛 D. chrysanthum & E & LC & $\mathrm{O} \& \mathrm{M}$ & 11 & & & & v, iii & $\mathrm{i}$ i, v & ii & ii & & $\begin{array}{l}\mathrm{v}, \\
\mathrm{iii}^{*}\end{array}$ & $\mathrm{iii}^{*}$ & $\mathrm{ii}$ & $\mathrm{ii}$ \\
\hline 鼓棺石斛 D. chrysotoxum & E & LC & $\mathrm{O} \& \mathrm{M}$ & 51 & $\begin{array}{l}\mathrm{i}, \mathrm{v}, \\
\text { vi, ii }\end{array}$ & $\begin{array}{l}\mathrm{i}, \mathrm{ii}, \\
\mathrm{v}, \mathrm{iii}\end{array}$ & $\begin{array}{l}\mathrm{i}, \mathrm{v}, \\
\mathrm{iv}, \\
\mathrm{iii}^{*}\end{array}$ & $\begin{array}{l}\mathrm{ii}, \mathrm{v} \\
\mathrm{iii}{ }^{*}\end{array}$ & $\begin{array}{l}\mathrm{i}, \mathrm{i}, \\
\mathrm{v}, \mathrm{iv}, \\
\mathrm{iii}{ }^{*}\end{array}$ & $\begin{array}{l}\text { ii,iv, } \\
\text { iii }\end{array}$ & ii, iii & iii & $\begin{array}{l}\mathrm{ii}, \mathrm{v}, \\
\mathrm{iii}\end{array}$ & $\begin{array}{l}i i, v, \\
i v, i i i\end{array}$ & $\begin{array}{l}\mathrm{i}, \mathrm{ii}, \\
\mathrm{iv}, \mathrm{iii}\end{array}$ & $\begin{array}{l}\text { ii, iv, } \\
\text { iii }\end{array}$ \\
\hline 玫瑰石斛 D. crepidatum & E & LC & $\mathrm{O} \& \mathrm{M}$ & 14 & & & $\begin{array}{l}\mathrm{i}, \\
i i^{*}\end{array}$ & $\begin{array}{l}\mathrm{i}, \mathrm{i} \text {, } \\
\mathrm{v}^{*}\end{array}$ & i, iv & $\mathrm{v}, \mathrm{iii}$ & $\mathrm{v}, \mathrm{iii}$ & & i & & & $\mathrm{v}, \mathrm{iii}$ \\
\hline
\end{tabular}


宋亚琼，刘芝龙，Sophie Willian，高江云. 西双版纳兰科植物集市贸易特点和保护启示. 生物多样性, 2017, 25 (5): 531-539. http://www.biodiversity-science.net/CN/10.17520/biods.2017022

\begin{tabular}{|c|c|c|c|c|c|c|c|c|c|c|c|c|c|c|c|c|}
\hline 晶帽石斛 D. crystallinum & $\mathrm{E}$ & $\mathrm{LC}$ & $\mathrm{O} \& \mathrm{M}$ & 10 & iii & & & $\mathrm{i}, \mathrm{v}, \mathrm{iii}$ & $\begin{array}{l}\mathrm{i}, \mathrm{i}, \\
\mathrm{v}, \\
i i^{*}\end{array}$ & $\mathrm{ii}^{*}$ & & & & & & iii \\
\hline 兒唇石斛 D. cucullatum & E & $\mathrm{LC}$ & O\&M & 12 & iii & & $i^{*}$ & $\mathrm{iii}^{*}$ & i, iii & $\mathrm{v}, \mathrm{iii}$ & iii & & i, iii & iii & & iii \\
\hline 叠鞘石斛 D. denneanum & E & EN & O\&M & 5 & & & & $\mathrm{iii}$ & $\mathrm{iii}^{*}$ & & & & $\mathrm{iii}$ & iii & & iii \\
\hline 密花石斛 D. densiflorum & E & VU & O\&M & 2 & & & & & & & & & $\mathrm{iii}$ & $\mathrm{iii}$ & & \\
\hline 齿辨石斛 D. devonianum & $\mathrm{E}$ & EN & $\mathrm{O} \& \mathrm{M}$ & 7 & iii & $\mathrm{v}$ & & $\begin{array}{l}\mathrm{v}, \\
i i^{*}\end{array}$ & $\mathrm{v}^{*}$ & & & & & $\mathrm{v}$ & & $\mathrm{iii}$ \\
\hline 黄花石斛 D. dixanthum & $\mathrm{E}$ & EN & $\mathrm{O} \& \mathrm{M}$ & 3 & & & & iii & & & & & & & $\mathrm{v}$ & $\mathrm{v}$ \\
\hline 反瓣石斛 D. ellipsophyllum & E & EN & $\mathrm{O} \& \mathrm{M}$ & 5 & & & & v, iii & $\mathrm{iii}^{*}$ & & & & iii & & & iii \\
\hline 串珠石斛 D. falconeri & $\mathrm{E}$ & EN & $\mathrm{O} \& \mathrm{M}$ & 5 & iii & & & & & $\mathrm{iii}^{*}$ & iii & & iii & & & iii \\
\hline 流苏石斛 D. fimbriatum & E & $\mathrm{VU}$ & $\mathrm{O} \& \mathrm{M}$ & 13 & & $\mathrm{i}, \mathrm{v}, \mathrm{iv}$ & $i i, i v$ & $\begin{array}{l}\mathrm{v}, \mathrm{iv} \\
\mathrm{iii}^{*}\end{array}$ & & $i v^{*}$ & & & $\mathrm{iii}$ & iii & & iii \\
\hline 杯鞘石斛 D. gratiosissimum & $\mathrm{E}$ & VU & $\mathrm{O} \& \mathrm{M}$ & 7 & iii & & & $i, i i i^{*}$ & $i i^{*}$ & & & & iii & iii & & iii \\
\hline 细叶石斛 D. hancockii & E & - & $\mathrm{O} \& \mathrm{M}$ & 1 & & & & i & & & & & & & & \\
\hline 苏辬石斛 D. harveyanum & $\mathrm{E}$ & vU & $\mathrm{O} \& \mathrm{M}$ & 3 & & & $\mathrm{v}^{*}$ & & & $\mathrm{v}$ & & & iii & & & \\
\hline 疏花石斛 D. henryi & E & EN & $\mathrm{O} \& \mathrm{M}$ & 1 & & & & & & & & & & & & $\mathrm{v}$ \\
\hline 尖刀唇石斛 D. heterocarpum & $\mathrm{E}$ & $\mathrm{VU}$ & $\mathrm{O} \& \mathrm{M}$ & 2 & & & & $\mathrm{iii}^{*}$ & i & & & & & & & \\
\hline 小黄花石斛 D. jenkinsii & E & LC & $\mathrm{O} \& \mathrm{M}$ & 9 & i, iii & & & $\mathrm{iii}^{*}$ & $\mathrm{iii}$ & iii & iii & & & & iii & \\
\hline 聚石斛 D. lindleyi & $\mathrm{E}$ & $\mathrm{VU}$ & $\mathrm{O} \& \mathrm{M}$ & 1 & i & & & & & & & & & & & \\
\hline 美花石斛 D. loddigesii & E & VU & O\&M & 1 & & & & & & & & & & iv & & \\
\hline 石斛 D. nobile & $\mathrm{E}$ & EN & O\&M & 42 & $\begin{array}{l}\mathrm{i}, \\
\mathrm{v}, \mathrm{iii}\end{array}$ & $\begin{array}{l}\mathrm{i}, \mathrm{v}, \mathrm{vi}, \\
\mathrm{iii}\end{array}$ & $\begin{array}{l}i, i i, \\
i v, i i i\end{array}$ & $\begin{array}{l}\mathrm{i} i, \mathrm{v}, \\
\mathrm{iv}, \mathrm{iii}^{*}\end{array}$ & $\begin{array}{l}\mathrm{i} i, \mathrm{v}, \\
\mathrm{iv}, \mathrm{iii}^{*}\end{array}$ & $\begin{array}{l}\text { i, ii, } \\
\text { iv, iii }\end{array}$ & $\begin{array}{l}\mathrm{i}, \mathrm{i} \text {, } \\
\mathrm{iii}\end{array}$ & i, iii & $\mathrm{i}, \mathrm{v}, \mathrm{iii}$ & $\begin{array}{l}\mathrm{v}, \mathrm{iv}, \\
\mathrm{iii}\end{array}$ & iv & $\begin{array}{l}\mathrm{v}, \mathrm{iv}, \\
\mathrm{iii}\end{array}$ \\
\hline 铁皮石斛 D. officinale & E & - & M & 1 & & & & & & & & & iii & & & \\
\hline 肿节石斛 D. pendulum & $\mathrm{E}$ & EN & $\mathrm{O} \& \mathrm{M}$ & 5 & $\mathrm{i}, \mathrm{iii}$ & $\mathrm{v}$ & $\begin{array}{l}\mathrm{i}, \\
i \mathrm{v}^{*}\end{array}$ & & & & & & & & & \\
\hline 报春石斛 D. polyanthum & $\mathrm{E}$ & $\mathrm{LC}$ & $\mathrm{O} \& \mathrm{M}$ & 14 & & $\mathrm{v}$ & $\begin{array}{l}i i, i v \\
i i i^{*}\end{array}$ & $\begin{array}{l}\mathrm{v}, \\
\mathrm{iii}^{*}\end{array}$ & $\mathrm{i}, \mathrm{v}, \mathrm{iii}$ & $\mathrm{v}, \mathrm{iii}$ & $\mathrm{iii}$ & & & & & iii \\
\hline
\end{tabular}


宋亚琼，刘芝龙，Sophie Willian，高江云. 西双版纳兰科植物集市贸易特点和保护启示. 生物多样性, 2017, 25 (5): 531-539. http://www.biodiversity-science.net/CN/10.17520/biods.2017022

\begin{tabular}{|c|c|c|c|c|c|c|c|c|c|c|c|c|c|c|c|c|}
\hline 剑叶石斛 D. spatella & $\mathrm{E}$ & vU & $\mathrm{O} \& \mathrm{M}$ & 2 & iii & & & iii & & & & & & & & \\
\hline 叉唇石斛 D. stuposum & E & EN & $\mathrm{O} \& \mathrm{M}$ & 1 & iii & & & & & & & & & & & \\
\hline 球花石斛 D. thyrsiflorum & $\mathrm{E}$ & LC & $\mathrm{O} \& \mathrm{M}$ & 53 & $\begin{array}{l}\text { i, ii, } \\
\text { v, vi, } \\
\text { iii }\end{array}$ & $\begin{array}{l}\text { i, ii, } \\
\text { vi, iii }\end{array}$ & $\begin{array}{l}\mathrm{i}, \mathrm{ii}, \\
\mathrm{iv}, \\
\mathrm{iii}^{*}\end{array}$ & $\begin{array}{l}\text { Ii , v, } \\
\text { iii }^{*}\end{array}$ & $\begin{array}{l}\mathrm{i}, \mathrm{ii}, \\
\mathrm{v}, \mathrm{iv}, \\
\mathrm{iii}^{*}\end{array}$ & $\begin{array}{l}\text { i, ii, v, } \\
\text { iv, ii }\end{array}$ & $\begin{array}{l}\mathrm{i}, \mathrm{ii}, \\
\mathrm{v}, \mathrm{iii}\end{array}$ & $\mathrm{iii}$ & $\begin{array}{l}\mathrm{ii,v}, \\
\mathrm{iii}\end{array}$ & $\begin{array}{l}\text { ii,iv, } \\
\text { iii }\end{array}$ & $\begin{array}{l}\text { ii, iv, } \\
\text { iii }\end{array}$ & $\begin{array}{l}\text { ii, v, } \\
\text { iii }\end{array}$ \\
\hline 翅梗石斛 D. trigonopus & $\mathrm{E}$ & LC & $\mathrm{O} \& \mathrm{M}$ & 10 & iii & & iii $^{*}$ & $\mathrm{iii}^{*}$ & iii & iii & iii & iii & iii & iii & & iii \\
\hline 大苍鞘石斛 D. wardianum & $\mathrm{E}$ & vU & $\mathrm{O} \& \mathrm{M}$ & 12 & & $\mathrm{v}, \mathrm{iii}$ & & $\mathrm{iii}^{*}$ & $i, i_{i}^{*}$ & iii & iii & & iii & iii & & iii \\
\hline 白绵线兰 Dendrolirium lasiopetalum & $\mathrm{E}$ & VU & $\mathrm{O}$ & 3 & & & & & & iii & iii & & iii & & & \\
\hline 线兰 D. tomentosum & $\mathrm{E}$ & LC & $\mathrm{N}$ & 4 & iii & & & & & $\mathrm{iii}$ & iii & & iii & & & \\
\hline 美冠兰 Eulophia dabia & $\mathrm{T}$ & - & $\mathrm{N}$ & 1 & i & & & & & & & & & & & \\
\hline 紫花美冠兰 E. spectabilis & $\mathrm{T}$ & vU & $\mathrm{O} \& \mathrm{M}$ & 3 & & & & $\mathrm{iii}^{*}$ & $\mathrm{v}, \mathrm{iii}^{*}$ & & & & & & & \\
\hline 滇金石斛 Flickingeria albopurpurea & $\mathrm{E}$ & LC & M & 4 & & & iv, iii & & & & & & i & i & & \\
\hline 大根槽舌兰 Holcoglossum amesianum & $\mathrm{E}$ & vU & $\mathrm{O} \& \mathrm{M}$ & 7 & iii & $\mathrm{iii}^{*}$ & & iii & ii & ii & ii & & ii & & & \\
\hline 湿唇兰 Hygrochilus parishii & $\mathrm{E}$ & LC & $\mathrm{O}$ & 7 & & & & & ii, iii & $\begin{array}{l}\mathrm{i}, \mathrm{ii}, \\
\mathrm{iii}^{*}\end{array}$ & $i^{*}$ & & $\mathrm{iii}$ & & & \\
\hline 长茎羊耳蒜 Liparis viridiflora & $\mathrm{E}$ & LC & M & 6 & ii, iii & & $\mathrm{ii}$ & $i \mathrm{i}, \mathrm{iv}$ & & & & & & & & \\
\hline 大花钔子股 Luisia magniflora & $\mathrm{E}$ & LC & M & 2 & iii & & & $\mathrm{iii}^{*}$ & & & & & & & & \\
\hline 钗子股 L. morsei & $\mathrm{E}$ & VU & $\mathrm{N}$ & 2 & & & & & $i i^{*}$ & $\mathrm{ii}$ & & & & & & \\
\hline 指叶拟毛兰 Mycaranthes pannea & $\mathrm{E}$ & LC & M & 2 & & & iii & & $\mathrm{v}^{*}$ & & & & & & & \\
\hline 剑叶㚜尾兰 Oberonia ensiformis & E & LC & $\mathrm{N}$ & 1 & & & & iii & & & & & & & & \\
\hline 全唇感尾兰 $O$. integerrima & $\mathrm{E}$ & LC & $\mathrm{N}$ & 3 & & & & & & & & & & iii & iii & iii \\
\hline 云南曲唇兰 Panisea yunnanensis & $\mathrm{E}$ & - & $\mathrm{N}$ & 2 & & & & & & & & & & & $\mathrm{iii}^{*}$ & \\
\hline 带叶淣兰 Paphiopedilum hirsutissimum & $\mathrm{E}$ & - & $\mathrm{O}$ & 1 & & & & $\mathrm{iii}^{*}$ & & & & & & & & \\
\hline 凤蝶兰 Papilionanthe teres & $\mathrm{E}$ & VU & $\mathrm{O} \& \mathrm{M}$ & 6 & & & & & $\mathrm{iii}^{*}$ & $\mathrm{iii}^{*}$ & iii & & iii & iii & & iii \\
\hline 虾尾兰 Parapteroceras elobe & $\mathrm{E}$ & VU & $\mathrm{N}$ & 2 & & & & & $\mathrm{ii}$ & ii & & & & & & \\
\hline 钻柱兰 Pelatantheria rivesii & $\mathrm{E}$ & LC & $\mathrm{N}$ & 3 & & & & & i & i & i & & & & & \\
\hline 仙笔鹤顶兰 Phaius columnaris & $\mathrm{T}$ & VU & $\begin{array}{c}\mathrm{O} \& \\
\mathrm{M}\end{array}$ & 2 & & & & iv & & & & & & iv & & \\
\hline
\end{tabular}


宋亚琼, 刘芝龙, Sophie Willian, 高江云. 西双版纳兰科植物集市贸易特点和保护启示. 生物多样性, 2017, 25 (5): 531-539. http://www.biodiversity-science.net/CN/10.17520/biods.2017022

\begin{tabular}{|c|c|c|c|c|c|c|c|c|c|c|c|c|c|c|c|c|}
\hline 节茎石仙桃 Pholidota articulata & E & LC & M & 10 & iii & & & iii & $\mathrm{iii}^{*}$ & $\mathrm{iii}^{*}$ & $\mathrm{iii}^{*}$ & $\mathrm{iii}^{*}$ & ii, iii & & & iii \\
\hline 石仙桃 P. chinensis & $\mathrm{E}$ & $\mathrm{LC}$ & M & 1 & & & & & & & & & & \multicolumn{2}{|l|}{ iii } & \\
\hline 宿苞石仙桃 P. imbricata & E & LC & M & 8 & iii & & iii & & iii & iii & $\mathrm{iii}^{*}$ & & $\mathrm{iii}^{*}$ & & & iii \\
\hline 云南石仙桃 P. yunnanensis & $\mathrm{E}$ & - & M & 1 & & & & & & & & & & \multirow{2}{*}{\multicolumn{2}{|c|}{$\mathrm{iii}^{*}$}} & \\
\hline 粗茎苹兰 Pinalia amica & E & LC & $\mathrm{N}$ & 4 & & iii & $\mathrm{v}^{*}$ & $\mathrm{ii}, \mathrm{v}^{*}$ & & & & & & & & \\
\hline 双点苹兰 P. bipunctata & $\mathrm{E}$ & LC & $\mathrm{N}$ & 2 & & & & & & iii & $\mathrm{iii}^{*}$ & & & & & \\
\hline 长苞苹兰 P. obvia & E & $\mathrm{LC}$ & $\mathrm{N}$ & 1 & & & & & & i & & & & & & \\
\hline 厚叶苹兰 P. pachyphylla & $\mathrm{E}$ & VU & $\mathrm{N}$ & 2 & & & & & & $i i^{*}$ & & & iii & & & \\
\hline 密花苹兰 P. spicata & E & LC & $\mathrm{N}$ & 4 & & & & & ii, iii & ii, iv & & & & & & \\
\hline 多穗兰 Polystachya concreta & $\mathrm{E}$ & VU & $\mathrm{N}$ & 1 & & & & iii & & & & & & & & \\
\hline \multirow[t]{2}{*}{ 钻潒兰 Rhynchostylis retusa } & \multirow[t]{2}{*}{$\mathrm{E}$} & \multirow[t]{2}{*}{ EN } & \multirow[t]{2}{*}{$\mathrm{O}$} & \multirow[t]{2}{*}{14} & & & \multirow[t]{2}{*}{ i, iii } & & \multirow[t]{2}{*}{$i i^{*}$} & i, ii, & i, ii, & \multirow[t]{2}{*}{ iii } & \multirow[t]{2}{*}{ ii, iii } & \multirow[t]{2}{*}{ iii } & & \multirow[t]{2}{*}{ iii } \\
\hline & & & & & & & & & & $\mathrm{iii}^{*}$ & iii & & & & & \\
\hline 大潒兰 Sarcoglyphis smithianus & E & LC & $\mathrm{N}$ & 2 & i & iii & & & & & & & & & & \\
\hline 掌唇兰 Staurochilus dawsonianus & $\mathrm{E}$ & LC & $\mathrm{O}$ & 3 & & & & & & $i, i i i^{*}$ & iii & & & & & \\
\hline 白点兰 Thrixspermum centipeda & $\mathrm{E}$ & $\mathrm{LC}$ & $\mathrm{O}$ & 1 & & & & ii & & & & & & & & \\
\hline 笋兰 Thunia alba & $\mathrm{T}$ & VU & $\mathrm{O} \& \mathrm{M}$ & 3 & & iii & iv & & $\mathrm{v}$ & & & & & & & \\
\hline 瓜子毛鞘兰 Trichotosia dasyphylla & E & LC & $\mathrm{N}$ & 1 & & & & & $\mathrm{iii}^{*}$ & & & & & & & \\
\hline 白柱万代兰 Vanda brunnea & $\mathrm{E}$ & LC & $\mathrm{O}$ & 12 & iii & $\mathrm{iii}$ & $\mathrm{iii}^{*}$ & & iii & $\mathrm{iii}$ & iii & & i, iii & i, iii & iii & iii \\
\hline 大花万代兰 V. coerulea & E & EN & $\mathrm{O}$ & 10 & $\mathrm{iii}$ & $\mathrm{iii}$ & & & iii & iii & iii & iii & iii & $\mathrm{iii}^{*}$ & & $\mathrm{iii}^{*}$ \\
\hline 矮万代兰 V. pumila & $\mathrm{E}$ & $\mathrm{LC}$ & $\mathrm{O}$ & 2 & iii & & & $\mathrm{iii}^{*}$ & & & & & & & & \\
\hline
\end{tabular}

生活型: E, 附生; T, 地生。濒危等级: EN, 濒危; VU, 易危; LC, 无危; DD, 数据缺失, 依据 Liu et al (2015)区域评估结果。用途: O, 观赏; M, 药用; N, 无目的用途。 i, ii, iii, $\mathrm{iv}, \mathrm{v}, \mathrm{vi}$ 为所调查的 6 个集贸市场。 $*$, 花期。

Life form: E, Epiphytic; T, Terrestrial. Endangerment category: EN, Endangered; VU, Vulnerable; LC, Least Concern; DD, Data Deficient; according to the results of Liu et al (2015). Usage: O, Ornamental; M, Medicina; N, Unclear. i, ii, iii, iv, v, vi are the trade markets investigated in this study. *, Flowering. 